\title{
The Role of Cellular Biology in Maxilo-facial Surgery and Protective Restorations
}

\author{
CRISTIAN ONISOR ${ }^{4}$, CRISTIAN CONSTANTIN BUDACU ${ }^{2 *}$, CARMEN ELENA COTRUTZ ${ }^{1}$, \\ VICTOR VLAD COSTAN ${ }^{2} *$, OANA ELENA CIURCANU ${ }^{2 *}$, IOAN SIRBU ${ }^{3}$, KAMEL EARAR ${ }^{4}$, \\ CATALIN PLESEA CONDRATOVICI ${ }^{4}$ \\ 1"Grigore T. Popa" University of Medicine and Pharmacy, Faculty Medicine, 16 Universitatii Str., 700115, Iasi, Romania \\ 2"Grigore T. Popa" University of Medicine and Pharmacy, Faculty of Dental Medicine, 16 Universitatii Str., 700115, Iasi, \\ Romania \\ ${ }^{3 e e}$ Carol Davila "University of Medicine and Pharmacy, Faculty of Dental Medecine, 37 Dionisie Lupu Street,020021, \\ Bucharest, Romania \\ 4"Dunarea de Jos" University of Galati, Faculty of Medicine and Pharmacy, 47 Domneasca Str., 800008, Galati, Romania
}

The essential characteristics of contemporary dental medicine are the precision, avant-garde, technologization and successful clinical purpose of cell therapy with the prospect of further application in the clinical practice of cell therapy methods and other performance methods based on the knowledge of cell biology and regenerative medicine in full function; despite the very different environments, such teeth can develop normal in adult jaw; thus, if suitable cells can be found that, by combination, produce immature teeth, there is the potential for bio-teeth to become a clinical reality.The maxillary frontal area represents the most important area of the maxillae from an aesthetic point of view and the prosthetic restoration of this area is of primary interest in ensuring the appearance, phonation, incision, in human communication and in the structuring of the individual personality. Affecting the maxillary frontal area or through coronary destruction consecutive cavities and their complications, discolouration, dental malpositions disgraceful or due to lack of dental periodontal units creates problem in the aesthetic prosthetics. These changes existing at the front arcade level cause major disturbances to the physiognomy, to the phonation. In the Clinic of Oral and Maxillofacial Surgery, in a period of 2 years, between 2016 and 2018, we noticed, solved and followed a number of 129 cases; 57 patients-lot endodontic and surgical therapy study; 72 patients, study group prosthetic restorations. Due to the functional role that the maxillary front teeth play, the corrections have to be made within the limits of functional tolerance that fall within the normal occlusal parameters because the functional disturbances dictated only by the aesthetics are not tolerated and can lead to large imbalances. The complex oral rehabilitation of the different clinical cases encountered in the dental practice is largely a challenge for the dentist due to the high degree of different affect but present on all the elements of the system.

Keywords: cell therapy method, regenerative medicine, prosthetic restoration

Dento - alveolar tissue is made up of various types of cells: ameloblasts, odonto - blasts, osteoblasts, cells specific to the dental pulp and the periodontal ligament.

Ameloblasts express proteins that are involved in amelogenesis, including amelogenin, ameloblastine, enamelin, and tuftelin. These proteins contribute to the mineralization of the enamel. Ameloblast biology, targeting apoptosis, differentiation, secretion, endocytosis, phagocytosis and calcium transport. Excessive fluoridation destroys the structure of the ameloblasts, by reducing the cellular organs, the expansion of the endoplasmic reticulum, the deformation of the mitochondria, the erosion of the cytoplasm, leading to apoptosis.

Odontoblasts represent post-mitotic cells that play a role in primary, secondary and tertiary dentin deposition [1-3].

Osteoblasts are involved in bone remodeling by synthesizing the bone matrix to maintain bone homeostasis, through proteins such as alkaline phosphatase and type I collagen, and cells in the periodontal ligament are involved in the remodeling of soft tissues to maintain the width of the periodontal ligament.

The periodontal ligament is made up of blood cells, endothelium and intercellular material, with fibroblast cells forming the collagen fibers involved in the repair and remodeling processes. In dental surgery - maxillo - facial surgery, monocytes and macrophages play an important role in dental resorption structures - alveolar in development and wound healing.

*email: cristibudacu@yahoo.com; victorcostan@gmail.com; oana.ciurcanu@umfiasi.ro 
Under the action of pro-inflammatory cytokines, monocytes appear in the areas of irritation and differentiate into macrophages. The activity of macrophages is influenced by the products resulting from the decomposition of the dento - alveolar bone and tissue structures, being controlled by the increased intracellular levels of adenosine 3, 5-cyclic monophosphate and calcium.

Cell biology investigates the physiological properties of cells as well as their behavior, interactions and environment. The experiments are performed both at the microscopic and molecular level. This field conducts research on single-celled organisms as well as on specialized cells in multicellular organisms such as human's.

What is fundamental to all sciences related to biology is to understand what cells are made of and how cells work. Knowing the similarities and differences is especially important in cell and molecular biology[4,5].

Developmental biology examines the processes by which organisms grow and develop. It has its origins in embryology ; it also studies the genetic control of cell growth, differentiation, anatomy and morphogenesis , the process that allows tissues and organs to appear and develop.

Bi olo gia is a system of disciplines studying the laws of life; researches the origin, development, complexity of living organisms.

In the oral and maxillofacial surgery, as in any other medical specialty, a complete examination of the patient is essential for establishing the diagnosis and therapeutic indication. This should include the thorough examination of the entire oromaxillofacial area as well as the general examination.

In this way one can detect the systemic origin of oro-maxillofacial lesions or the consequences of dento-periodontal or maxillofacial disorders on other organs or systems.

On the other hand the clinical examination in conjunction with paraclinic examination makes possible to evaluate the status of general condition of the body in order to indicate or coner indicate surgery in oral or maxillofacial territory.

In patients whose pathological field (hemorrhagic diathesis, heart disease, liver disease, diabetes, etc. ) can lead to various complications (local and general), oral and maxillofacial surgery can be performed after an appropriate pre-training under ambulatory conditions.

In edentulous situations at the level of the maxillary frontal group, the fixed prosthetic restoration must be restored by means of a bridge body, the dental absence. If the edentation is older, it determines the resorption of the edentulous ridge, the artificial tooth must be longer, the papillae are gone and in their place black spaces appear, empty which all compromise aesthetically the prosthetic reconstruction [6,7].

In the planning treatment the model diagnosis and the waxing work to visualize the physiognomic effect, will ensure an optimal design of the prosthetic work [8-10].

The loss of the volume of the residual edentulous ridge is related to the aesthetic aspect of the black triangle, instead of the dental structure by the absence of the soft tissue, food and percolation impact, the projection of the saliva, in the phonetic articulation $[11,12]$.

Apical resection is the surgical intervention that removes the apex part of the root, along with the pathological elements around it. It has the purpose of removing the apical and periapical pathological outbreak, in order to make possible the correct filling of the root canal.

From the point of view of tooth preservation, apical resection is a valuable procedure in avoiding premature edentation, being considered as a surgical method that comes to aid of conservative endodontic therapy. The operation is life-saving when other conservative treatment methods have failed to cure periapical lesions[14,15].

\section{Experimental part}

\section{Materials and methods}

In the Clinic of Oral and Maxillofacial Surgery, in a period of two years, between 2016-2018, we noticed, solved and followed up a number of 129 cases; 57 patients-lot endodontic and surgical therapy study; 72 patients, study group prosthetic restorations.

Of these $69(53.48 \%)$ were men and 60 women $(46.52 \%)$ and the age ranged between 18-65 years, with the highest incidence between $45-60$ years.

The study presents the importance of the methods of preservation of teeth with aesthetic and prosthetic importance, highlighting the role of the surgical therapy and the immediate prosthesis in maintaining the balance of the stomatognathic system, by the morphological and functional restoration in order to prevent the complications due to the altered oral health.

Of the 129 cases, 57 had periapical conditions: acute apical periodontitis suppurated; periapical suppurations; periapical cysts suppurated; suppurations of superficial lodges. 
Following the clinical and radiological examination, for these patients the initial diagnosis was established: chronic periapical osteitis, periapical granuloma, small periapical cyst.

Whenever the periapical pathology subsists under the conditions of an endodontic treatment considered to be correct, by endodontic surgery - in this case apical resection, the apical and periapical pathological outbreak can be removed, thus creating the conditions for the healing of the periapical pathological processes, for restructuring; the apical resection avoids the extraction of the causal tooth, keeping a situation as favorable as possible for the future prosthetic works.

Due to the high weights of the periapical pathology, we consider that by establishing the diagnoses criteria and the therapeutic variants, we can obtain the retention of the tooth over a longer period; by the loss of the odonto-periodontal units changes occur at the level of the component elements of the stomatognathic system, regardless of the cause or amplitude of the edentation.

Conservative treatment is more easily accepted by some patients, but involves multiple therapy sessions and the result may be unsatisfactory.

Surgical treatment is preferred by some patients because it is a rapid variant.

For the study of prosthetic restorations the sample was represented by 72 patients. After establishing the diagnosis, they were given specific treatments depending on the lesions presented.

The etiological factor that determined the patients to resort to the dental treatment was represented by: coronary destruction in a number of 47 cases $(65.27 \%)$; color changes in 19 cases $(26.38 \%)$; morphological changes presented 6 cases $(8.33 \%)$.

In terms of lesion location, most affected upper front teeth: central incisors, lateral incisors, canines and lower frontal teeth.

In the case of the multifactorial etiology, the addressability distribution was: old fillings $22 \%$, dischromas $2 \%$, secondary caries $18 \%$, abrasion $13 \%$, other coronary disorders $8 \%$, structural changes $2 \%$, traumatic fractures $2 \%$, anomalies $2 \%$.

The therapeutic option was: metal-ceramic microprotheses, metal-composite microprotheses, full ceramic microprotheses, used in patients with coronary defects, patients with color changes, patients with morphological changes.

The facet was used in 11 patients, all with color changes.

Affection of the maxillary frontal area either by coronary damage following caries and their complications, discolorations, disastrous dental malpositions or due to the absence of dental-periodontal units create problems of aesthetic prosthetics.

These changes in the frontal arch cause major disorders of the appearance, phonation and incision ability of the food. Clinically, there are subjective and objective signs related to the functional aspects exhibited, intensely accused by the patients and that dictate the presentation to the doctor for treatment [16-18].

The practical possibilities of aesthetic prosthetic restoration of the fronto-maxillary area are represented in the situation of coronary dental lesions that allow the preservation of the odonto-periodontal units can be used: ceramic inlays of class III or IV, cast side, ceramic-metal crown, crown all ceramics; in the case of the existence of an edentation in the maxillary frontal area this can be treated by: adhesive bridge on inlay, adhesive bridge on cast facets, physiognomic dental bridge, bridge with ovate aesthetic bridge body; fixed prosthesis on implants. One of the biggest challenges for dental practitioners who perform crowns and physiognomic restorations is the need to match expectations regarding the achievable technical and aesthetic element.

A new study published in the Journal of Dent of Research describes progress in the forces of developing a method of replacing missing teeth with new teeth created by bioengineering of cells from the person's own gums. The study is led by Professor Paul Sharpe, an expert in craniofacial development and stem cell biology at King's College London Dental Institute.

Studies aiming at the production of teeth through bioengineering (biodinents) have been largely focused on the generation of immature teeth that mimic those in the embryo and can be transplanted as small "balls" of cells into the adult jaw to develop teeth fully functional.

Other subsequent studies, recently conducted, have focused largely on the use of embryonic cells, but such cellular sources are impractical for use in general dentistry. Researchers are trying to find an adult source of epithelial and mesenchymal cells that can be obtained in large numbers enough for bio- teeth created to become a viable alternative to dental implants.

In this new study, researchers have isolated cells from adult human patients, they have multiplied in the laboratory and then combine them at cell generating teeth from mice cells.

By transplanting these combinations with mice cells, the researchers managed to grow hybrid teeth containing viable dentin, enamel and root .

Researchers have concluded that these easy- to-obtain epithelial cells are a good source to consider for the formation of human bio- teeth. 
But the big challenge is discovering a method of modifying adult human mesenchymal cells to be tooth generators, because at the moment only the mesenchymal cells are embryonic.

In order to produce a replacement tooth, Japanese researchers at the Tokyo University of Science have extracted, from mouse embryos, embryonic cells that were supposed to give birth to teeth. The cells were implanted into the kidney of an adult mouse. After two months, a normal molar developed from the cells, also with the periodontal ligament (the fibers through which the tooth is attached to the bone in the jaw).

The researchers extracted the tooth and implanted it in the lower jaw of another mouse. After 30 days, the blood vessels and nerves around the transplanted tooth worked just as well as in a tooth that would have grown there. Of course, the fact that cells extracted from the embryos are needed and that the tooth has been grown in the kidney prevents, for now, the use of the method in humans. But other experts believe that similar results could be obtained using stem cells from adults or cells from the jaws, and the next step would be to identify a method to grow cells that will give birth to the replacement tooth.

\section{Conclusions}

The aesthetic and prosthetic importance of the teeth in the fronto-maxillary area is major, considering that all the methods of conservative-endodontic, surgical, prosthetic treatment are essential.

The maxillary frontal area represents the most important area of the jaws from an aesthetic point of view and the prosthetic restoration of this area is of primary interest in ensuring the appearance, the phonation, the incision, in the human communication and in the structure of the individual personality.

\section{References}

1.FORNA N. Evaluarea Starii de Sanatate Afectate prin Edentatie, Editura Demiurg, 2007.

2.FORNA N. Tratat de Protetică Dentară, Editura "Gr.T.Popa", 2008.

3.IMAI Y, SATO T, MORI S, OKAMOTO M. A histomorphometric analysis of bone dynamics in denture supporting tissue under continuous pressure. J Oral Rehab, 2002; 29: 7279.

4.OWALL B, BUDTZ-JÖRGENSEN E, et al, Removable partial denture design: A need to focus on hygienic principles? Int J Prosthodont 15:371$78,2002$.

5.ANDREI M, DINISCHIOTU A, DIDILESCU AC, IONITA D, DEMETRESCU I. Periodontal materials and cell biology for guided tissue and bone regeneration. Annals of Anatomy-Anatomischer Anzeiger.2018 Mar 1;216:164-9.

6.NIKOLIDAKIS D, JANSEN JA. The biology of platelet-rich plasma and its application in oral surgery:literature review. Tissue Engineering Part B: Reviews. 2008 Sep 1;14(3):249-58.

7.SALMON CR, GIORGETTI AP, LEME AF, DOMINGUES RR, KOLLI TN, FOSTER BL, NOCITI Jr FH.

8.***Microproteome of dentoalveolar tissues. Bone. 2017 Aug 1;101:219-29.

9.BABAJI P, DEVANNA R, JAGTAP K, CHAURASIA VR, JERRY JJ, CHOUDHURY BK, DUHAN D. The cell biology and role of resorptive cells in diseases: a review. Annals of African medicine. 2017.Apr;16(2):39.

10. CHECHERITA, L. E., FORNA, N.C., MACOVEI, SURDU,A. et al.Influence of Chemical Therapeutical Methods on Manducatory

Muscles,Rev.Chim.(Bucharest), 64, no.11, 2013, p. 1312-1316

11.DASCALU, C.G., ANTOHE, M.E., GOLOVCENCU L., et al.,Interaction Schemes for the Analysis of Combined Action of Risk Factors,2017

IEEE International Conference on e-health and Bioengineering Conference (EHB) Book Series: E-Health and Bioengineering Conference,

2017, Pages: 462-465

12. CIOCAN-PENDEFUNDA,A.A.,MARTU,M.A.,ANTOHE,M.E.et al.,Indirect composite veneers as a social therapeutic solution.A case report, Romanian Journal Of Oral Rehabilitation, 10 (4), 2018 Pages: 91-96

13.GRADINARU, I., ANTOHE M.E., HURJUI, L.L,Biomaterials used in oral rehabilitation of the edentulous allergic patients, Romanian Journal of Oral Rehabilitation,10(1),2018, Pages: 114-119

14.SCUTARIU, M. M., CIURCANU, O. E., FORNA AGOP,D., et al.,Importance of dental maxillo-facial aesthetics in dental therapy, MedicaLSurgicalJournal Volume: 120 Issue: 4 ,2016, Pages: 926-931

15. SALCEANU, M., VATAMAN, M., AMINOV, L. et al., Diagnosis and follow-up of the periapical lesions in the non-surgical endodontic treatment:a CBCT study, Romanian Journal of Oral Rehabilitation, 9 (2), 2017, pag :32-36,

16. CHECHERITA .L.E., FORNA N.C., STAMATIN O.et al.,Correlations between biochemical parameters integrated in stomatognathic system dysfunctional syndrome, Rev. Chim. (Bucharest), 64, no. 10, 2013, p. 1172-1181

17. SAVEANU, C.I., FORNA, N.C., DANILA, I.et al.,Management attitudes of dentists in dental offices, Romanian Journal of Oral Rehabilitation, 10(4), 2018, pg.149-156

18. ESANU, I., CONSTANTIN, I., BUDACU, C.C., et al., The role of chemical factors in the diabetes and the prediabetes that leads to polimorfe oro-maxilo-facial alterations inmalformative syndrome, Rev. Chim.(Bucharest), 70, no.6, 2019, p. 2112-2117

Manuscript rceived: 3.12.2019 